\title{
Factors That Influence Instructors' Integration of Social Media Platforms Into Higher Education Pedagogy in Ghana
}

\author{
Patricia Ananga (Corresponding author) \\ University of Education, Winneba, Ghana \\ Tel: 233-543-044-818Ｅ-mail: patricia.ananga1@gmail.com
}

Received: July 19, 2020 Accepted: August 21, 2020 Published: September 5, 2020

doi:10.5296/jei.v6i2.17367ＵRL: https://doi.org/10.5296/jei.v6i2.17367

\begin{abstract}
Higher Education (HE) institutions have been exploring new approaches that will enable them to manage with the increasing demand of access to education. One key area is in the usage of new models, new innovations, and new ways of delivering the curriculum, connecting students with their instructors such as the use of Social Media (SM) in teaching. This paper examined the factors that influence instructors' use of SM in Ghanaian HE pedagogy. The study employed the concurrent triangulation mixed method approach using questionnaire and semi-structured interview guide to obtain data from two hundred and thirty-five (235) instructors who were selected using the multistage sampling technique from the University of Education, Winneba (UEW) and the Ghana Technology University College (GTUC). The key findings point to the fact that instructors' professional rank, intrinsic drive, functionality of SM platforms, user friendliness, motivation, ease of use of the SM platforms, access to internet connection and ease of communication in using the platforms were the factors that influenced instructors use of SM for teaching. The study concludes by indicating the implications of the findings for policy on the use of SM for delivering instruction in Ghana and recommends the need for HE authorities to come up with motivational packages that would encourage instructors to integrate SM into the pedagogy of HE in Ghana.
\end{abstract}

Keywords: Social Media (SM), Higher Education (HE), Pedagogy, Curriculum, Innovations, Models

\section{Background}

Formal teaching and learning have traditionally been considered mainly, on the use of physical structures where students and instructors meet in face-to-face sessions for instructional delivery to take place. This necessitates the need for physical infrastructure and 
resources such as classrooms, instructional materials and more importantly, the physical presence of instructors and students (Staines, 2013).

Under this type of method, it is a pre-requisite for institutions to invest in infrastructure and other resources to ensure that effective teaching and learning take place. This method makes it difficult to plan and implement instruction beyond physical space. It is important to indicate that the global demand for Higher Education (HE) is increasing at a faster rate (OECD, 2012), which is changing the HE landscape. Higher education institutions have been exploring new approaches that will enable them to manage with this increasing demand of access for education. One key area is in the usage of new models, new innovations, and new ways of delivering the curriculum, connecting students with their instructors, and measuring outcomes. In developing countries like Ghana, the growth in population as well as the insufficient educational infrastructure and resources (human and material), have made it necessary to adopt and implement other educational forms (Tagoe, 2012). These include the use of emerging Information Communication Technologies (ICTs), which have been found as great tools that encourage students in particular to pursue knowledge and contribute to knowledge creation for quality instruction (Bingimlas, 2009; Hamidi, Meshkat, Rezaee, \& Jafari, 2011).

Some of these emerging technologies include Social Media (SM), which have been explored and used in education. Several studies have highlighted the relevance of SM for teaching and learning purposes with huge benefits to learners, instructors, and education institutions (e.g., L. W. Friedman \& H. H. Friedman, 2013; Lin, Homman, \& Borengasser, 2013; Tang \& Whinston, 2012; Dubrovsky, 2011; Maccini, Gagnon, \& Hughes, 2002). Generally, studies have provided several factors that influence the use of ICTs and SM for teaching and learning. These include the functionality of the SM platform as far as the platform's ability to support teaching and learning is concerned (Jewitt, Hadjithoma-Garstka, Clark, Banaji, \& Selwyn, 2010). Other factors are SM's interactive ability (Alabdulkareem, 2015); ease of use in terms of SM's comfortability to users (Arkorful \& Abaidoo, 2007; Bora \& Ahmed, 2013) and another critical element known as social pressure (Bora \& Ahmet, 2013).

There is evidence of the extensive studies that have been conducted globally on the use of SM for teaching and learning as well as the factors that influence users' (students and instructors) adoption of SM for instructional purposes. On the contrary, there is a dearth of evidence on the Ghanaian HE landscape so as far as the factors that influence instructors' use of SM is concerned. A few of the studies in Ghana for instance, have looked at other factors that rather influence teachers' adoption and integration of information and communication technology into teaching in general (Buabeng-Andoh, 2012). Others (e.g., Adu-Manu, Arthur, \& Yeboah, 2013; Apeannti \& Essel, 2013; Otu, 2015; Ocansey, Ametepe, \& Oduro, 2016) that were conducted in the field of SM, focused mainly on the role and impact of SM, leaving the factors that influence instructors usage of SM for teaching and learning. The current study therefore sought to examine the factors that influence instructors' use of SM for teaching and learning in Ghana. 


\subsection{Literature Review}

Several factors including age, gender, motivation, academic programme and professional ranking, have been found to account for the use of SM in teaching and learning. For example, many studies have shown that age has a significant influence on the way SM tools are used for personal and professional purposes, the general trend being that the older instructors with over 20 years of teaching experience, compared to their younger colleagues, are less likely to use SM tools for their courses (e.g., Parry, 2010; Blankenship, 2011; Ruleman, 2012; Moran, Seaman, \& Tinti-Kane, 2012; Roebuck, Siha, \& Bell, 2013; Mutekwe, 2015; Velsamy \& Karthikeyan, 2016). However, interestingly, other commentators hold opposing views. Indeed, some studies have found that educators of all ages use SM equally. Blankenship (2011), for example, revealed that older instructors with 20 years or more of teaching experience use SM just as much as their younger colleagues. Similarly, Ruleman (2012) even found that older male and female instructors used SM more extensively than their middle-aged counterparts.

Another key factor influencing SM usage in education that has caught the attention of researchers is gender (Siha \& Bell, 2013; Roebuck, Siha \& Bell, 2013; Huang, Hood, \& Yoo, 2013; Agbatogun, 2013; Ruleman, 2012; Neely, 2011; Goudreau, 2010). For instance, in a study that examined instructors' usage of SM and mobile devices, Roebuck, Siha and Bell (2013) sought to understand the perceptions of professors who used SM for instruction, the type of mobile devices used in accessing SM, what motivated the use of SM, and the enthusiasm and/or reservations instructors showed with regard to SM usage. Adopting a two-way multivariate analysis of variance (MANOVA) to investigate possible gender differences, it emerged that while $67.2 \%$ of SM users in the sample were female only $32.8 \%$ were male. This suggests that more females use SM than their male counterparts, a conclusion corroborated by Goudreau's (2010) finding that 57\% of Facebook users are female, which means that they are more likely to use ICT tools than their male counterparts (Ruleman, 2012). Nevertheless, other researchers have achieved different results, with evidence of no substantial correlation between academic rank, gender and SM usage (Kim, Kwon, \& Cho, 2011; Agbatogun, 2013).

Other criteria that have been identified as influencing SM usage habits of educators are personal intrinsic motivation, field of study (Parry, 2010), academic rank (Agbatogun, 2013), attitude (Mutekwe, 2015), personal and peer resistance (Sigalit, Sivia, \& Michal, 2016), and other factors such as psychological characteristics, information quality, social influence, and system usefulness. Regarding what motivates professors to adopt SM in their instruction, the three most common responses found by Parry (2010) were personal initiative: 67\%; enthusiasm for ICT development: 58\%; and the wishes of students 48\%. Parry (2010) argues that it is surprising that student demand only comes third considering that learners should be at the centre of any instructional process. The author assumes that this was a comparatively less popular motivational criterion because the students under study were already fully conversant with the use of SM and consequently thought their professors might want to keep up with them and would thus be motivated to employ SM tools, whereas the professors had already chosen to use SM for personal intrinsic reasons and so were motivated to adopt it in their instruction. 
Additionally, the field of study (academic programme) cannot be overlooked as a factor that influences instructors' choice of the use of SM for teaching (Parry, 2010). In this regard, the humanities and social sciences have been found to represent greater SM usage among faculty members than that cited by their colleagues in the fields of mathematics, business studies, or the natural sciences. Finally, Mutekwe (2015) also identifies the attitude of HE educators to ICT use in the classroom as one of the strongest predictors of whether or not an HE institution will make a policy decision to officially integrate the application of SM into its curriculum.

\subsection{Context of and Aim of Study}

The study context was the University of Education, Winneba and the Ghana Technology University College. Both institutions have integrated technology into their teaching and learning delivery, thus, circumstances around ICT-particularly SM usage in these two institutions were of significant interest to the study. The aim of this study was to examine the factors that influence instructors' use of SM platforms into the pedagogy of HE in Ghana.

\subsection{Research Question}

The question that guided this study was:

What factors influence instructors' use of SM platforms into HE pedagogy?

\subsection{Theoretical Framework}

To examine the factors that influence instructors' use of SM platforms into HE instructional delivery, this study drew on the Technological Pedagogical Content Knowledge (TPACK) model (Harris, Mishra, \& Koehler, 2009). TPACK considers the successful integration of technology as mostly entrenched in curriculum content, content related learning processes, and the appropriate use of educational technologies (Harris, Mishra, \& Koehler, 2009). The interplay of the elements of TPACK is ensured by instructors because they are the drivers, facilitators, and guides of student learning. Therefore, to ensure that technology is integrated into instruction successfully, instructors plan and consider the requirements of the curriculum, students' learning needs, the efficacy of the technologies available, and the realities of classroom and school contexts. Thus, Harris, Mishra, and Koehler (2009) identify technology, pedagogy and content knowledge as enablers whereby instructors may address the complexities of lesson planning with the use of SM. These elements: (1) Pedagogical Content Knowledge (PCK), which encompasses the way specific content-based materials are taught; (2) Technological Content Knowledge (TCK), which deals with the selection of appropriate technologies to support specific content-based instructions; (3) Technological pedagogical Knowledge (TPK), which focuses on the use of specific technologies for teaching; and (4) Technological Pedagogical Content Knowledge (TPACK), which hinges on teaching particular content-based material with the use of appropriate and specific technologies that are suitable for the content, as well as matching student needs and preferences appropriately. TPACK is the foundation of effective teaching with technology. It requires the understanding of concepts using technologies, the pedagogical techniques that employ constructive use of technologies to teach content to aid student understanding of concepts. It finally considers 
students' previous knowledge of content and knowledge about the use of technologies in building existing knowledge to develop new epistemologies or strengthen old ones (Koehler \& Mishra, 2009). It is important to consider certain variables such as demographics, school-specific factors, culture, individual instructors, and other related factors. Thus, no individual combination of content and pedagogy will apply to all instructors, each perspective on teaching, or every course. Applying TPACK to SM integration in Ghanaian HE instructional delivery, therefore, means that it is critical to consider the factors that influence instructors in any given specific context.

\section{Methodology}

This study was conducted in alignment with the pragmatist paradigm because I believe that there are nuances in our perceptions of reality and, for that matter, it was necessary to be alternately objective and subjective in order to capture all of the various aspects of the factors that influence instructors' use of SM in Ghanaian HE. Pragmatism, which bridges the two research traditions of quantitative and qualitative inquiry, is concerned with the issue of combining both approaches (Creswell \& Plano Clark, 2011; Saunders, Lewis, \& Thornhill, 2009). The resultant mixed methods approach therefore allows for the collection of a rich and broad range of data through the examination of complex phenomena in social and natural contexts (Creswell, 2009; Morgan, 2007). Thus, I sought to unravel the complex phenomenon of the factors that influence students' and instructors' use of SM for teaching and learning through mixed methods inquiry. This study employed the concurrent triangulation mixed-methods design (Creswell et al., 2003; Creswell \& Plano Clark, 2011) to explore the research problem in its entirety (Ponce \& Pagan-Maldonado, 2015). The study context was the University of Education (UEW) in Winneba and the Ghana Technology University College (GTUC) in Accra. Both institutions have integrated technology into their teaching and learning delivery, thus, circumstances around ICT-particularly SM usage in these two institutions were of significant interest to the study.

The population for the study comprised all undergraduate instructors and the target population was undergraduate instructors from three faculties of each of the two institutions. The multistage sampling was employed. Firstly, expert purposive sampling was used to select three faculties from UEW. Conversely, a homogenous sampling technique was used to select all the three faculties from GTUC because it is a technology university. Next, the instructors were stratified into ranks (Lecturer, Senior Lecturer, and Professor). The simple random sampling technique was then used to select $30 \%$ from the total population of both institutions (UEW instructors - 136 out of a population of 454; GTUC-99 out of a population of 330). According to Mugenda and Mugenda (2003) and Mugenda and Mugenda (2013), a sample size of 10\% and $30 \%$ is considered as a good representation of the target population and therefore appropriate for analysis when the population of the study is less than 10,000. The total number of instructors was, therefore, 235. The convenience sampling was finally used to select two participants each from the three professional ranks from both institutions (six from UEW and six from GTUC), making 12 altogether, for a face-to-face and telephone interview where appropriate. 
Items for the instruments used in data collection were constructed for both qualitative and quantitative approaches. Due to the nature of the study, a survey questionnaire and in-depth interviews were administered to participants. These methods were used as a means of accessing different data sources and facilitated the triangulation of data to validate the findings (Punch, 2002). I obtained the necessary ethical clearance and permission from the University of Ghana Ethics Committee for the Humanities, Legon, Accra. UEW and GTUC authorities were respectively contacted to seek permission to conduct the study, and approval was granted. I then submitted a consent form to each research site requesting the participation of instructors. All participants were assured of confidentiality and anonymity before the data collection process began.

A pilot study was conducted to validate the quantitative study instruments. Ten instructors and sixty students were sampled. The items were peer-reviewed to ensure that they were clear and unambiguous. The data was analysed to ensure full validity and reliability of the instruments before the main study was conducted. The results from the pilot helped to reframe some of the items which were quite ambiguous and could not yield reliable responses.

Data collection instruments were administered for both methods at the same time but independently. A rapport was established with participants before the instruments were administered to gain their confidence. The purpose of the exercise was then introduced. The qualitative elements of the study were therefore conducted with the application of principles that would ensure the trustworthiness of the data which is critical in ascertaining the value of qualitative research and the validity and reliability of research instruments (Lincoln and Guba, 1985; Trochim, 2007). Thus, to ensure the reliability of the field data, the qualitative component of this study adopted Lincoln and Guba's (1985) model of trustworthiness as follows: Confirmability, Transferability, Credibility and Dependability.

\subsection{Data Analysis, Findings and Discussions}

The qualitative data was analysed using content analysis. It provided separate explanations as to the various themes that were developed in the unstructured interview items. It is important to note that due to the nature of the design (triangulated mixed-methods), the qualitative and quantitative components of the data were collected and analysed separately before the datasets were merged and finally integrated for synthesis and development of narrative descriptors.

A preliminary data analysis of the quantitative data was done to screen and examine the data. After this, a test of normality using skewness and kurtosis (-2 to 2: George \& Mallery, 2010) was conducted. Exploratory factor analysis was also conducted. The data were analysed separately in respect of the various themes developed by the survey items. Inferential and descriptive statistics - such as frequency tables, means, standard deviation (SD), t-tests, inter-correlation matrix, ANOVA, hierarchical multiple regression, and MANOVA-were used to describe demographic characteristics (age, sex, instructor's professional rank, programme of study, area of specialisation, number of years as an instructor, etc.) of participants. 


\subsection{Influence of Demographic Factors on Students' and Instructors' SM Usage}

Instructors were asked to indicate their agreement with statements about their engagement in activities that involved SM usage by rating the activities on a scale of one to five (i.e., strongly disagree to strongly agree). The responses were aggregated, and the mean SM usage scores were computed and used as a proxy measure of their SM usage (i.e., extent to which they agreed to educational engagement in SM activities). The mean SM usage scores were used to further group students into those indicating high [i.e., mean $>3.4$ ] or low [i.e., mean $\leq 3.0$ ] agreement to educational engagement in SM activities.

Table 1. Distribution of respondents' rating of their SM usage by category of the demographic factor (percentages and standard deviation in parentheses)

\begin{tabular}{|l|l|l|l|l|}
\hline \multirow{2}{*}{} & & \multicolumn{3}{|c|}{ Number of instructors } \\
\cline { 3 - 5 } & Low usage & High usage & Mean (SD)2 \\
\hline \multirow{4}{*}{ Gender } & Female & $1(6)$ & $15(94)$ & $4.0(0.35)$ \\
\cline { 2 - 5 } & Male & $3(9)$ & $29(91)$ & $3.93(0.38)$ \\
\hline \multirow{4}{*}{ Discipline } & $<25 /(<30)$ & $0(0)$ & $0(100)$ & $4.11(0.5)$ \\
\cline { 2 - 5 } & $25-30 /(30-40)$ & $3(19)$ & $13(81)$ & $3.9(0.44)$ \\
\cline { 2 - 5 } & $>30 /(>40)$ & $1(4)$ & $27(96)$ & $3.96(0.31)$ \\
\hline \multirow{5}{*}{ Years of Usage } & STEM & $2(7)$ & $27(93)$ & $4.0(0.37)$ \\
\cline { 2 - 5 } & Non-STEM & $2(10)$ & $17(90)$ & $3.88(0.36)$ \\
\hline & $5-10$ & $1(50)$ & $1(50)$ & $4.03(0.66)$ \\
\cline { 2 - 5 } & $>10$ & $1(5)$ & $20(95)$ & $3.93(0.34)$ \\
\hline \multirow{5}{*}{ Years of teaching } & $<5$ & $2(8)$ & $23(92)$ & $3.99(0.33)$ \\
\cline { 2 - 5 } & $5-15$ & $1(20)$ & $3(80)$ & $3.72(1.01)$ \\
\cline { 2 - 5 } & $>10$ & $3(10)$ & $27(90)$ & $3.97(0.31)$ \\
\hline & All Respondents & $4(8)$ & $44(92)$ & $3.96(0.37)$ \\
\hline
\end{tabular}

Table 1 shows a cross tabulation of participants' (instructors) SM usage categories (i.e., high or low) by demographic factor (i.e., gender, age, discipline, and years of usage) as well as descriptive statistics. The results from Table 1 indicate that on all demographic factors, the proportion of respondents with high SM usage is far greater than those with low SM usage. Overall, nearly all (i.e., 92\%) instructors had high SM usage for educational purposes, with only about $8 \%$ having low SM usage. With respect to gender as a factor for instance, it was observed that, over $90 \%$ of females and males had high educational SM usage for their academic work. 


\section{1l Macrothink}

The lesser years (less than 5 years) instructors had used SM more than those who had used SM for more than ten years. To ascertain whether or not the differences observed in terms of instructors' ratings of mean educational usage of SM were statistically significant, the data were subjected to further analysis using an independent samples t-test and a one-way ANOVA to test the following hypothesis as indicated in Table 2:

There is no significant difference between or among categories of demographic factors (i.e., gender, age, discipline, and years of usage) in the ratings of instructors' SM usage.

Table 2. Independent samples t-test for the difference between categories in gender and discipline in respondents' ratings of SM usage.

\begin{tabular}{|l|l|l|l|l|l|l|l|}
\hline & & & $\mathrm{M}$ & $\mathrm{SD}$ & $\mathrm{t}$-value & Df. & Sig. (2-tailed) \\
\hline \multirow{4}{*}{ Instructors } & \multirow{3}{*}{ Gender } & Female & 3.70 & 0.48 & \multirow{2}{*}{0.625} & \multirow{2}{*}{46} & \multirow{2}{*}{0.535} \\
\cline { 3 - 9 } & \multirow{2}{*}{ Male } & 3.66 & 0.50 & & & \\
\cline { 3 - 9 } & \multirow{2}{*}{ Discipline } & STEM Disciplines & 3.70 & 0.51 & \multirow{2}{*}{1.134} & \multirow{2}{*}{46} & \multirow{2}{*}{0.262} \\
\cline { 3 - 8 } & & Non- STEM Disciplines & 3.61 & 0.46 & & & \\
\hline
\end{tabular}

Note. Significant at $* \mathrm{p}<0.05$.

Source: Field Data, 2018.

The results of the independent samples t-test on the differences between the categories of dichotomous demographic factors (i.e., gender and discipline) in the ratings of instructors' SM usage are shown in Table 2. The results indicate that there was no significant difference in instructors' ratings of SM usage in the categories of gender and discipline. This implies that gender and discipline (i.e., whether a STEM-related discipline or not) does not influence instructors' educational use of SM. The results of the ANOVA on the differences between categories of non-dichotomous demographic factors (i.e., age, programme level, years of usage, and years of teaching in the case of instructors) in the ratings of SM usage are shown in Table 3. 


\section{Macrothink}

Journal of Educational Issues

ISSN 2377-2263

2020, Vol. 6, No. 2

Table 3. Independent samples t-test of the difference between categories in gender and discipline in respondents' ratings of SM usage (*Mean difference significant at the 0.05 level.)

\begin{tabular}{|c|c|c|c|c|c|c|c|c|}
\hline Factor & Category & Group & Mean (SD) & $\begin{array}{l}\text { Sum of } \\
\text { squares }\end{array}$ & Df. & $\begin{array}{l}\text { Mean } \\
\text { square }\end{array}$ & $\mathrm{F}$ & Sig. \\
\hline \multicolumn{9}{|c|}{ Instructors } \\
\hline \multirow{3}{*}{ Age } & $<25$ & Between & $4.11(0.5)$ & 0.141 & 2 & 0.070 & 0.509 & 0.604 \\
\hline & $25-30$ & Within & $3.9(0.44)$ & 6.214 & 45 & 0.138 & & \\
\hline & $>30$ & Total & $3.96(0.31)$ & 6.354 & 47 & & & \\
\hline \multirow{3}{*}{ Years of Usage } & $<5$ & Between & $4.03(0.66)$ & 0.121 & 2 & .060 & .436 & .649 \\
\hline & $5-10$ & Within & $3.93(0.34)$ & 6.234 & 45 & .139 & & \\
\hline & $>10$ & Total & $3.99(0.33)$ & 6.354 & 47 & & & \\
\hline \multirow{3}{*}{ Years of teaching } & $<5$ & Between & $3.72(1.01)$ & 0.066 & 2 & 0.033 & 0.237 & 0.79 \\
\hline & $5-10$ & Within & $3.97(0.31)$ & 6.288 & 45 & 0.140 & & \\
\hline & $>10$ & Total & $3.96(0.37)$ & 6.354 & 47 & & & \\
\hline
\end{tabular}

Note. Significant at $* \mathrm{p}<0.05$.

Source: Field Data, 2018.

To further address the question of what influenced instructors to use SM in their teaching, a hierarchical multiple regression was used. Prior to the use of the hierarchical multiple regression, Pearson $r$ test was employed to establish possible correlations between variables. The Pearson $r$ test also checked for the existence of multicollinearity was. Summaries of the results of the Pearson $r$ test and the hierarchical multiple regression are shown in Tables 4 and 5, respectively. 


\section{Macrothink}

Table 4. Summary of the intercorrelation matrix between instructor variables $\left({ }^{*} \mathrm{p}<0.05,{ }^{* *} \mathrm{p}<\right.$ $0.01)$

\begin{tabular}{|l|l|l|l|l|l|l|l|l|l|}
\hline & 1 & 2 & 3 & 4 & 5 & 6 & 7 & 8 & 9 \\
\hline SM Usage & 1.000 & & & & & & & & \\
\hline Institution & $-0.220^{* *}$ & 1.000 & & & & & & & \\
\hline Sex & -0.061 & 0.005 & 1.000 & & & & & & \\
\hline Age & $0.214^{* *}$ & $-0.195^{* *}$ & 0.019 & 1.000 & & & & & \\
\hline Years of teaching & $0.112^{*}$ & $-0.104^{*}$ & -0.067 & $0.629^{* *}$ & 1.000 & & & & \\
\hline Rank & $0.101^{*}$ & -0.059 & 0.005 & $0.697^{* *}$ & $0.725^{* *}$ & 1.000 & & & \\
\hline SM integrated & 0.032 & $0.120^{*}$ & -0.034 & -0.038 & $-0.109^{*}$ & -0.008 & 1.000 & & \\
\hline Opportunities & $0.339^{* *}$ & $-0.132^{*}$ & 0.039 & $0.157^{* *}$ & 0.021 & 0.060 & 0.069 & 1.000 & \\
\hline Challenges & $-0.141^{* *}$ & $0.109^{*}$ & 0.022 & -0.070 & $0.161^{* *}$ & -0.022 & $-0.172^{* *}$ & -0.061 & 1.000 \\
\hline
\end{tabular}

Note. Significant at ${ }^{*} \mathrm{p}<0.05, * * \mathrm{p}<0.01$.

Source: Field Data, 2018.

Table 4 shows that except for the correlation between rank and years of teaching-which reveals a correlation coefficient greater than 0.70 -all other correlations are less than 0.70 . This indicates that there is no multicollinearity between variables. Table 4 also shows that institution, age, years of teaching, professional rank, opportunities, and challenges correlate significantly with SM usage $[\mathrm{r}=.220, .214, .112, .101, .339,-.141 ; \mathrm{p}<0.05$ respectively]. Such correlation between most variables and the lack of multicollinearity warranted further statistical analysis of the data to determine what specifically influenced instructors' usage of SM as shown in Table 5. 


\section{Macrothink}

Table 5. Summary of hierarchical multiple regression showing predictors of SM usage by instructors

\begin{tabular}{|l|l|l|l|l|l|}
\hline & Beta & $\mathrm{T}$ & $\mathrm{P}$ & $\mathrm{R}^{2}$ & $\mathrm{~F}$ change \\
\hline Step 1: & & & & $.09^{* *}$ & 4.69 \\
\hline Gender & -.07 & -1.07 & .28 & & \\
\hline Age & .23 & 2.59 & .01 & & \\
\hline Years of teaching & -.01 & -.13 & .90 & & \\
\hline Institution & -.18 & -2.90 & .00 & & \\
\hline Rank & -.06 & -.62 & .54 & & \\
\hline Step 2: & & & & $.18^{* *}$ & 14.69 \\
\hline Gender & -.07 & -1.12 & .25 & & \\
\hline Age & .15 & 1.68 & .09 & & \\
\hline Years of teaching & .07 & .78 & .44 & & \\
\hline Institution & -.14 & -2.32 & .02 & & \\
\hline Rank & -.08 & -.83 & .41 & & \\
\hline Opportunities & .30 & 5.07 & .00 & & \\
\hline Challenges & -.11 & -1.82 & .07 & & \\
\hline
\end{tabular}

Note. Significant at $* \mathrm{p}<0.05, * * \mathrm{p}<0.01$.

Source: Field Data, 2018.

As shown in Table 5, demographic variables (gender, age, years of teaching, rank and institution) contribute $9 \%$ of changes in instructors' SM usage $\left[\mathrm{R}^{2}=0.09, \mathrm{p}<0.01\right]$. When opportunities and challenges were introduced into the model, as indicated in step 2, they collectively contribute $18 \%$ of changes in instructors' $S M$ usage $\left[\mathrm{R}^{2}=0.18, \mathrm{p}<0.01\right]$. However, only the opportunities variable significantly predicts instructors' SM usage $[\beta=.30, p<0.01]$. Further to the statistical analysis, a MANOVA was also employed to test the influence of demographic variables on instructors' SM usage. The result of which is shown in Table 6. 


\section{Macrothink}

Table 6. Summary of MANOVA showing differences in instructors' SM usage by demographic variables a. $\mathrm{R}$ Squared $=.243$ (Adjusted R Squared $=.128$ )

\begin{tabular}{|l|l|l|l|l|l|}
\hline Source & Type III Sum of squares & Df. & Mean square & F & Sig. \\
\hline Corrected Model & $13.945 \mathrm{a}$ & 34 & .410 & 2.110 & .001 \\
\hline Intercept & 900.573 & 1 & 900.573 & 4632.972 & .000 \\
\hline Gender & .225 & 1 & .225 & 1.159 & .283 \\
\hline Institution & .043 & 1 & .043 & .219 & .640 \\
\hline Teaching & .972 & 3 & .324 & 1.668 & .175 \\
\hline Rank & 1.910 & 4 & .478 & 2.457 & .047 \\
\hline Error & 43.348 & 223 & .194 & & \\
\hline Total & 3916.551 & 258 & & & \\
\hline Corrected Total & 57.292 & 257 & & & \\
\hline
\end{tabular}

Source: Field Data, 2018.

Table 6 indicates that demographic variables (gender, institution, years of teaching and rank) explain $24.3 \%$ of changes in instructors' SM usage $\left[\mathrm{R}^{2}=.243\right]$. However, Table 6 also reveals that professional rank is the only demographic variable that significantly influenced SM usage, implying that instructors' usage of SM is strongly influenced by their professional rank. To establish precise differences in SM usage by programme of study, a multiple comparison analysis was conducted, which is shown in Table 7.

Table 7. Summary of multiple comparison analysis showing differences in instructors' SM usage by instructors' professional rank

\begin{tabular}{|l|l|l|l|}
\hline \multicolumn{5}{|c|}{ Instructors' SM usage on their Professional Rank } \\
\hline Professional Rank & $\mathbf{1}$ & $\mathbf{2}$ & $\mathbf{3}$ \\
\hline Lecturer & - & & \\
\hline Senior lecturer & -.002 & - & \\
\hline Professor & $\mathbf{. 2 5 3}$ & $\mathbf{. 2 5 4}$ & - \\
\hline
\end{tabular}

Table 7 shows that, there are some significant differences in the professional ranks regarding instructors' SM usage. Thus, professors use SM more than lecturers (.253) and senior lecturers (.254). 


\subsection{Instructors' Views on the Factors That Influence Their Use of SM}

Instructors from the two institutions were asked to indicate certain factors that influenced their choice of SM platforms for teaching. In view of this, they expressed their views on what essentially inspired them to use a given platform, with particular reference to any possible restrictions they experienced. Some of the key issues that emerged from respondents' (instructors) narratives included the functionality of a platform, its accessibility, ease of communication with other users, access to Internet connectivity, ease of use, user friendliness, convenience, and personal drive.

\subsubsection{Functionality of Platforms}

Participants indicated that the ability of SM platforms to perform specific functions was essential in their readiness to use them. If SM platforms did not meet their needs by helping them to execute their roles, then they would rather choose other platforms that would help them to meet those needs. For instance, a female ICT instructor from UEW noted that:

One factor I can talk about is functionality of the platform. That is the platform's ability to perform the specific function I want it to perform for me at a particular point in time. If it's ok, then I will use it. There are some platforms that have limitations on what you can do and what you cannot do. One of them is Snapchat. That one ... there are a lot of limitations, like you can't move media from that platform to your gallery and so on and so forth...so it makes it very restricted. [IP5]

\subsubsection{Platform Accessibility}

Access to SM platforms was another factor that respondents indicated as influential in their choice to use a platform. Thus, any SM platform that they would want to use should be easily accessible to them and also help them to reach the people they wanted for various purposes:

One factor that will make me use social media platforms would be accessibility to the platforms, which is how easy we [can] lay hands on that platform. This is very important to me, and I think I mostly use WhatsApp, for example, due to how easy I am able to access both the platform and the people I want to reach: I do not need to navigate too much. [IP6]

\subsubsection{Ease of Communication with Other Users}

Ease of communication with other users was another key factor that was identified by the majority (6 of 12) of instructor participants. According to them, some platforms enabled them to communicate with their contacts more easily, especially their students, and that prompted them to use these platforms. Prominent among such platforms were WhatsApp, Google+ and Facebook:

Communication is a key factor in my case... So, there are certain types of platforms where I have a lot more communication coming through that makes me check messages a lot more or use it more than other platforms, like WhatsApp. In that sense, then, I end up using those ones a bit more... to communicate. [IP11] 
The platform's capability to help me reach people and communicate is very key... So, those kinds of things ... yes, I suppose what would probably drive me to use, will be how easy it is for me to interact or communicate with the other partner. [IP3]

\subsubsection{Ease of Use}

According to some participants, the choice of SM platforms for teaching was linked to their ease of use, that is, how simple or complex it was to communicate with their students. According to an instructor from GTUC, students were prone to SM usage and were very comfortable using it, and that for him was a strong driving force for wanting to use SM for teaching. Another instructor at UEW emphasised that she chose platforms based on the extent to which they helped her share learning materials with her students:

My motivating drive to use social media is ease of use, especially how easy it helps me to reach my students... Students these days use social media more, so why not engage them in using things that they are comfortable using; drawing their minds away from misusing it and, rather, focusing on something beneficial like learning. Getting them to use things they are comfortable using already will make it easier ... So, ease of use. [IP9] GTUC

I choose what will make my work easy. Sometimes, I don't have to meet them in class to be able to share certain information or certain assignments, or whatever... it makes it easier sharing course materials and all that with my students. You just send it through the Whats App group, and they get it ... [IP5] UEW

\subsubsection{Access to Internet Connectivity}

Participants also saw access to Internet connectivity as another factor that was crucial to whether they used SM. In their narratives, they indicated that connectivity to the Internet should be fast and reliable and without hitches:

Yes, Internet connectivity is very paramount. I use social media a lot on my phone. I use WhatsApp on my laptop or on my tablet, I use Telegram on my tablet and I normally transfer files from my phone to my tablet and to other devices all the time, so normally connectivity should be very reliable to do that. [IP2]

... let me say connectivity, it is towards connectivity, how easy it is for me to get Internet to be able to use social media is very relevant. [IP8]

\subsubsection{Convenience of the Platforms}

On the issue of convenience as a factor, respondents indicated that they used the platforms which they found convenient to use. That encouraged them to want to continue with their use in teaching:

How convenient it is for me to use a said social media platform is important to me... For example, social media's ability to provide convenience with features that I can use in my teaching, send course materials, do assignments, get content ... [IP10]

I would say that I would choose a particular social media platform if it is convenient for 
me to use. If I see that the platform is suitable for me, I will use it, if not I won't bother myself with it at all. [IP6]

\subsubsection{Intrinsic Drive}

Intrinsic drive, as in motivation that sprang from the individual as a desire to use a particular tool, was mentioned by some instructors, especially those who were IT orientated and taught ICT-related courses. Such instructors had a flare for technology and were consequently attracted to use SM platforms. For instance, an IT instructor from GTUC said that:

I will say that I intrinsically like technology... and so I like to make use of technology, so if I see an app or any technology tool like social media that will make my life easier, I am easily for it. [IP8]

I think I am personally motivated to use social media for my teaching ... errm you see I like using it because I love using it [IP4]

\subsubsection{Speed}

Another intriguing factor that respondents indicated as influencing them to use SM platforms in interacting with their students was speed and how quick students were able to access whatever information or resources that was crucial to them:

Speed is very crucial to me; how...fast the students will access whatever I post there. So, for that matter, mobile-based platforms like WhatsApp, Telegram, probably if I am sending them a message and want them to see it quickly, then I will be driven to use those platforms for quick access. [IP8]

The rate at which information and resources I send to my students can be accessed and spread quickly within a twinkle of an eye is a key motivating factor. [IP12]

\subsubsection{User Friendliness}

Participants touched on the issue of a platform's user friendliness as a key factor and it emerged that any tool they wanted to use needed to be straight forward to use. One instructor from the Department of Business Administration at UEW, for instance, mentioned in his narrative that Twitter was 'unfriendly' as far as he was concerned and so he was not inclined to use it; rather, he was more drawn to WhatsApp because it was more user friendly, while others supported her views:

There is this term called user friendliness and that is very important to me...because there is this particular one that is not too user friendly to me, like Twitter, so I don't really fancy going there ... But WhatsApp is such that a lot of people are able to use it provided you can type and read ... [IP6]

Features on a platform that enable me to perform a particular activity is a key factor to me. For example, if I want to just send information to my students or colleagues, I know WhatsApp can help me do that easily, so I choose that due to the features. If I need to send a multimedia file on a tutorial, of course, YouTube video. Like if it is something that 
I want to be seeing and explaining to my students, then probably is the video that explains something better... Yes, multimedia, I will probably go for YouTube, so the features of the platform is critical here. [IP2]

The demographic factors applied in this study such as, gender of instructors; age, academic programme, professional ranking, and the number of years of SM usage were tested to determine level of SM usage. However, the findings revealed that the gender, age, programme taught by instructors, years of teaching, and years of digital media usage by instructors had no influence on their usage of SM. Equally, the gender of instructors did not have any influence on their usage of SM for teaching. These findings are corroborated by the studies of Kim, Kwon, and Cho (2011), and Agbatogun (2013), both of which reveal no substantial correlation between gender and SM usage for educational purposes. However, the findings revealed that an instructor's professional rank has an influence on his SM usage. This implies that instructors' professional rank influence them to use SM platforms for teaching. This is corroborated by Agbatogun (2013).

The study's findings reveal other factors, such as relevance or functionality of a given SM platform, communication, easy access to information, interactivity of the platform, level of control users have in accessing platforms, the general indifference to technology of some instructors, and opportunities and challenges as SM is used for teaching. Instructors indicated that their readiness or otherwise to use SM platforms depended fundamentally on the ability of a platform to provide what they needed, that is, to perform the functions they desired. On the issue of functionality as a key factor in the use of SM, instructors believed that platforms needed to perform certain functions, such as helping them to establish facts, learn more about what colleagues and students were thinking, and other things they wanted to use the platforms for. This implies that the purpose of SM is to perform particular functions at particular times, and so the capacity of a given platform to help users perform those functions is critical in deciding whether or not they would use it for various instructional purposes.

Another factor that emerged was a platform's ability to aid communication. Communication was very important to instructors. In fact, they emphasised that since there was always the need to communicate issues such as instructional schedules and other important announcements among themselves and with their students, the feature of an SM platform that enabled the educational community communicate amongst its members was critical in influencing instructors to either use the platform or not.

Furthermore, information flow was found to be a factor which particularly had to do with sharing and receiving resources like educational files and documents. Thus, instructors' willingness to use any given SM platform hinged on its ability to ensure the free flow of all necessary information (Mura, Nuri, \& Naseeb, 2016). In this regard, it was revealed that instructors experienced freedom in accessing SM in the sense that they did not report many restrictions on its usage. Therefore, ease of use as well as ease of access prompted the use of SM. However, some platforms were found to be more accessible and easily used than others. Thus, the choice of a particular platform was influenced by how easy or difficult it was to access and use. These findings accord with Mura, Nuri, and Naseeb (2016), who found that 
psychological characteristics, information quality, social influence, and system usefulness were leading factors that could motivate users to use SM platforms for educational purposes.

Instructors indicated that apart from the fact they were intrinsically motivated (Parry, 2010) to use SM for their professional development as well as their teaching, the current generation of students or digital natives (Prensky, 2001) were very comfortable with the use of technological tools (Katai, 2015) like SM. Therefore, the instructors were sufficiently influenced to use SM to enhance their teaching and also to make learning interesting for their students.

Finally, it became apparent that opportunities as well as challenges were revealed in the findings as critical factors or predictors of SM usage for instructional purposes. According to the findings, the opportunities that instructors saw as manifesting in their use of SM platforms prompted them to use and continue to use the platforms for various instructional activities and vice versa.

\section{Conclusion and Recommendations}

This study showed that SM plays a critical role in the delivery of higher education instruction in the $21^{\text {st }}$ century since it caters for the needs of the learner. The paper examined the factors that influenced the integrating of SM platforms into higher education pedagogy.

The factors that influence SM use by instructors for teaching, were determined in the study as, motivation (intrinsically and extrinsically), instructors' professional rank, number of years of teaching, motivation, and access to Internet connection. These findings showed that for instructors to decide to use SM platforms for teaching there should be sufficient positive factors to convince them to do so. This implies that higher education will have to motivate instructors to deepen their usage of SM for teaching. There is the need to also improve on the infrastructural resources that will make instructors want to use SM for teaching.

Based on the findings of the study, the following policy recommendations are made:

- There is the need for a paradigm shift in the use of SM for instructional delivery in Ghanaian HE.

- In advocating for the use of SM in teaching, it is most necessary for HE authorities to come up with motivational packages that would be tied to the promotion of instructors. For instance, several credits could be assigned to the delivery of instruction using SM. This could be ascertained by checking the number of hours instructors teach and interact with their students using SM. It is anticipated that such motivational packages would encourage instructors, especially those who are initially apathetic towards the use of SM, to be more open to this innovative tool.

- There is also the need to improve the internet infrastructure to help the easy access to SM for teaching. 


\section{References}

Agbatogun, A. (2013). Interactive digital technologies' use in Southwest Nigerian universities. Educational Technology Research \& Development, 61, 333-357. https://doi.org/10.1007/ s11423-012-9282-1

Alabdulkareem, S. (2015). Exploring the use and the impacts of social media on teaching and learning science in Saudi. Procedia-Social and Behavioral Sciences, 182(1), 213-224. https://doi.org/10.1016/j.sbspro.2015.04.758

Arkorful, V., \& Abaidoo, N. (2007). The role of e-learning, the advantages and disadvantages of its adoption in higher education. International Journal of Education and Research, 2(12), $397-410$.

Bingimlas, K. A. (2009). Barriers to the Successful Integration of ICT in Teaching and Learning Environments: A Review of the Literature. Eurasia Journal of Mathematics, Science and Technology Education, 5(3), 235-245. https://doi.org/10.12973/ejmste/75275

Blankenship, M. (2011). How social media can and should impact higher education. Education Digest: Essential Readings Condensed for Quick Review, 76(7), 39-42.

Bora, U., \& Ahmed, M. (2013). E-Learning using cloud computing. International Journal of Science and Modern Engineering, 1(2), 9-13.

Buabeng-Andoh, C. (2012). Factors influencing teachers' adoption and integration of information and communication technology into teaching: A review of the literature. International Journal of Education and Development using Information and Communication Technology, 8(1), 136-155.

Creswell, J. W. (2009). Research Design: Qualitative, Quantitative and Mixed Method Approaches (3rd ed.). Los Angeles: SAGE Publications.

Creswell, J., \& Plano Clark, V. L. (2011). Conducting and Designing Mixed Methods Research (2nd ed.). Thousand Oaks, CA: Sage.

Dubrovsky, D. (2011). Human Nature, the anthropological crises and global future. Journal of Social Sciences, 13(1), 201-208.

Freidman, L. W., \& Friedman, H. H. (2013). Using social media technologies to enhance online learning. Journal of Educators Online, 10(1), 12-19. https://doi.org/10.9743/JEO. 2013.1.5

Goudreau, J. (2010). What men and women are doing on Facebook. Retrieved from http://www.forbes.com/2010/04/26/popular-social-networking-sites-forbes-woman-time-face book-twitter.html

Hamidi, F., Meshkat, M., Rezaee, M., \& Jafari, M. (2011). Information technology in education. Procedia Computer Science, 3, 369-373. https://doi.org/10.1016/j.procs.2010. 12.062 
Harris, J. B., Mishra, P., \& Koehler, M. (2009). Teachers' technological pedagogical content knowledge: Curriculum-based technology integration reframed. Journal of Research on Technology in Education, 41(4), 393-416. https://doi.org/10.1080/15391523.2009.10782536

Jewitt, C., Hadjithoma-Garstka, C., Clark, W., Banaji, S., \& Selwyn, N. (2010). School use of learning platforms and associated technologies. University of London, London.

Kim, J., Kwon, Y., \& Cho, D. (2011). Investigating factors that influence social presence and learning outcomes in distance higher education. Computers \& Education, 57(2), 1512-1520. https://doi.org/10.1016/j.compedu.2011.02.005

Lin, M. G., Homman, E. S., \& Borengasser, C. (2013). Is social media too social for class? A case study of Twitter use. Tech Trends, 57(2). https://doi.org/10.1007/s11528-013-0644-2

Lincoln, Y. S., \& Guba, E. G. (1985). Naturalistic Inquiry. Newbury Park, CA: Sage Publications. https://doi.org/10.1016/0147-1767(85)90062-8

Maccini, P., Gagnon, J. C., \& Hughes, C. A. (2002). Technology-Based practices for secondary students with learning disabilities. Learning Disability Quarterly, 25(4), 247-261. https://doi.org/10.2307/1511356

Matukwe, E. (2015). Higher Education and the Social Media Technology: A Dilemma Unfolding in Institutions of Higher Learning. Journal of Education and Human Development. American Research Institute for Policy Development, 4(3), 119-133.

Moran, M., Seaman, J., \& Tinti-Kane, H. (2012). Blogs, Wikis, Podcasts and Facebook: How Today's Higher Education Faculty Use Social Media. Boston: Pearson Learning Solutions.

Morgan, D. L. (2007). Paradigms lost and pragmatism regained: methodological implications of combining qualitative and quantitative methods. $J$ Mixed Methods Res, 1, 48-76. https://doi.org/10.1177/2345678906292462

Mugenda, O. M., \& Mugenda, A. G. (2003). Research Methods: Quantitative and Qualitative Approaches. Nairobi: African Centre for Technology Studies.

Mugenda, O. M., \& Mugenda, A. G. (2013). Research methods: Quantitative and qualitative approaches. Nairobi: ACTS Press.

National Center for Education Statistics. (2005). State non-fiscal public elementary/secondary education survey. American Counselling Association.

Neely, L. S. (2011). An analysis of Facebook intensity and privacy management practices of public-school educators in the United States. ProQuest Information \& Learning.

Ocansey, K., Ametepe, W., \& Oduro, C. F. (2016). The Impact of Social Media on the Youth: The Ghanaian Perspective. International Journal of Engineering Technology and Sciences, 6(1), 87-97. https://doi.org/10.15282/ijets.6.2016.1.12.1062

OECD. (2012). Education at a Glance 2012: OECD Indicators. OECD Publishing. https://doi.org/10.1787/eag-2012-en 


\section{Macrothink}

Otu, A. A. (2015). Social Media Addiction among Students of the University of Ghana (Doctoral dissertation, University of Ghana).

Parry, M. (2010). Most professors use social media. The Chronicle of Higher Education. Retrieved from http://chronicle.com/blogs/wiredcampus/most-professors-use-social-media/ 23716

Ponce, O. A., \& Pagan-Maldonado, N. (2015). Mixed methods research in education: Capturing the complexity of the profession. International Journal of Educational Excellence, l(1), 111-135. https://doi.org/10.18562/IJEE.2015.0005

Punch, S. (2002). Research with Children: The same or different from research with adults? Childhood, 9(3), 321-341. https://doi.org/10.1177/0907568202009003005

Roebuck, D. B., Siha, S., \& Bell, R. L. (2013). Faculty usage of social media and mobile devices: Analysis of advantages and concerns. Interdisciplinary Journal of E-Learning and Learning Objects, 9, 171-192. https://doi.org/10.28945/1914

Ruleman, A. (2012). Social media at the university: A demographic comparison. New Library World, 113(7), 316-332. https://doi.org/10.1108/03074801211244940

Saunders, M., Lewis, P., \& Thornhill, A. (2009). Research Methods for Business Students. Pearson, New York.

Sigalit, W., Sivia, B., \& Michal, I. (2016). Factors associated with nursing students' resilience: Communication skills course, use of social media and satisfaction with clinical placement. Journal of Professional Nursing, 153-161. https://doi.org/10.1016/j.profnurs.2016. 08.006

Staines, G. (2013). The benefits of cloud computing in education are huge! Retrieved April 26, 2015, from http://blogs.aspect.com/?s=advantages + of + cloud+computing\&search_submit. $\mathrm{x}=0$ \&search_submit. $\mathrm{y}=0$

Tagoe, M. (2012). Students' perceptions on incorporating E-learning into teaching and learning at the University of Ghana. International Journal of Education and Development Using Information and Communication Technology, 8(1), 91-103.

Tang, B. G., \& Whinston, A. (2012). Content contribution of social media: The case of You Tube. Hawaii International Conference on Systems Sciences, 2 (1), 4476-4485.

Trochim, W. (2007). The Research Methods Knowledge Base. Atomic Dog and Cengage Learning.

Velsamy, A., \& Karthikeyan, P. (2016). Social Media in the Professional Development of B-School Faculty. International Journal of Innovative Research in Management Studies, 1, 62-71. 


\section{Copyright Disclaimer}

Copyright for this article is retained by the author(s), with first publication rights granted to the journal.

This is an open-access article distributed under the terms and conditions of the Creative Commons Attribution license (http://creativecommons.org/licenses/by/3.0/). 